\title{
Impact of Parental Cancer on Children
}

\author{
BINAY K. SHAH ${ }^{1,2}$, JEFFERY ARMALY ${ }^{2}$ and ERIN SWIETER ${ }^{2}$ \\ ${ }^{I}$ North Puget Cancer Center, Sedro-Woolley, WA, U.S.A.; \\ ${ }^{2}$ Pacific Northwest University of Health Sciences College of Osteopathic Medicine, Yakima, WA, U.S.A.
}

\begin{abstract}
Background/Aim: The majority of cancers affect the elderly, but $22.4 \%$ of all cases occur in the ages of 21-55. This age range represents common childbearing and child-rearing years, which imply that many of these patients have minor children. Approximately 2.85 million children under 18 live with a parent affected by cancer. Materials and Methods: The Pubmed and Google Scholar were searched to identify literature on impact of parental cancer on children and potential interventions to support parents and children. Results: We reviewed impact of parental cancer on daily routine, role changes, emotional problems and social functioning of children. We also discuss interventions that may be useful for parents and children. Conclusion: It is essential that we learn more about the impact of parental cancer on children and ways to support the families using evidence-based interventions.
\end{abstract}

It is estimated that $10.4 \%$ of newly diagnosed cancer patients are between the ages of $18-55$, with $22.4 \%$ of all cancer cases occurring in individuals aged 21-55 (1). This range represents common childbearing and child-rearing ages which suggest a significant portion of these patients may have minor children. In fact, in 2010 it was estimated that 2.85 million children under the age of 18 lived with a parent who was diagnosed with cancer in the US (2). Over the last 30 years, overall cancer survival rates have increased with the 5-year survival rate rising $20 \%$ across all races (3). The increasing survival rates suggest a concomitant increase in prevalence of cancer survivors with minor children.

A cancer diagnosis can affect the whole family, not just the afflicted parent $(4,5)$. Multiple studies demonstrate that children

This article is freely accessible online.

Correspondence to: Dr. Binay Kumar Shah, North Puget Cancer Center, 2000 Hospital Drive, Sedro-Woolley, WA, U.S.A. 98284. Tel: +1 3608566021, Fax: +1 360856752, e-mail: binay.shah@gmail.com

Key Words: Cancer, children, psychology, review. in particular have a higher risk of emotional and behavioral problems $(6,7)$. The disruption of schedules and daily routine, shifting of household roles, financial stress, and the physical and emotional availability of either parent all contribute to these emotional and behavioral problems (7-9). These problems, if overlooked or untreated, can persist into adulthood (10).

\section{Daily Routine}

A daily routine is an important part of life for preschoolers, grade-schoolers, and adolescents for both structural stability and social behavior guidance $(7,11)$. A parental cancer diagnosis can disrupt the daily routine or schedule due to frequent clinic visits, unexpected hospital admission, and the home turning into a place of care $(9,12,13)$. The disruptions also promote problems sleeping in preschoolers and increased post-traumatic stress symptoms as well as internalizing and externalizing behaviors in adolescents $(6,7,14)$. Adolescents also report the impact that physical unavailability has on their emotional well being including the ill parent no longer driving them to school, to extracurricular activities, or even packing lunches $(12,15)$.

\section{Role Changes}

It has long been known that parental roles change as one parent becomes a caregiver and the ill parent becomes less available physically and emotionally, having fewer opportunities to interact while placing increased demands on their children (12). However, children of patients with cancer frequently change roles within their family as well, absorbing more responsibility while one parent cares for the ill parent $(4,16)$. The literature shows that both children and adolescents have increased personal responsibilities, resulting in a decrease in social activity and subsequent loss of childhood at a time when peer groups are essential for social development $(4,10$, 14, 17). Adolescent truancy rates increase and overall attendance decreases as they need to care for their younger siblings or pick-up extra work shifts to help combat the financial burden cancer puts on a household $(11,13)$. 


\section{Emotional Problems}

The psychological and behavioral changes observed in children and adolescents can be categorized as internalizing problems, affecting the mental, cognitive, or emotional functioning and externalizing problems, which include outward directed aggression or disruptions in a social or school setting $(7,13,16)$. Preschool children have an increased difficulty in separating from their mothers, while children of all ages display a wide range of emotions including anger, anxiety, confusion, sadness, uncertainty, and fear $(3,7,11)$. Elementary school-aged children express guilt, as they feel responsible for their parent's illness, and are more affected by the visible changes in their ill parent, such as hair loss and frequent vomiting (4, 6, 11). Elementary-aged boys exhibited higher anxiety and hostility while girls demonstrated increased internalizing behaviors (13). Adolescents are particularly at risk, as shown in a couple studies with adolescents between ages 11-18 that found up to $21 \%$ of boys and $35 \%$ of girls reported clinically significant post-traumatic stress symptoms (PTSS) $(6,8,13$, 18). Self reports of psychological issues, externalizing problems, and internalizing problems of depression and anxiety are higher than parental perceptions of the same problems (13). This age group is typically more concerned with the well-being of the parent and begins to focus on the parent's well being more than their own individual well being $(11,13)$. Multiple studies report adolescent females at higher risk, experiencing more internalizing problems including depression and anxiety, which was increased if their mother had cancer, due to concerns of long-term implications and chances of inheritance $(4,5,9,13)$. Many children want to protect their parents, and try to cope by using diversion and denial (19). Unfortunately, stressful life events may increase conditions such as breast cancer risk (20-22).

\section{Social Functioning}

Preschoolers rely on positive family functioning and exhibit distressed behaviors when their family cohesiveness is altered $(13,14)$. Parents also report that frequent appointments and intense treatment plans further increase their anxiety and depression, which decreases parenting efficiency and thus, family functioning $(13,23,24)$. Primaryschoolers and adolescents, especially daughters, are affected by the mental health and coping techniques of their parents, and learn accordingly (18). Parents and teachers both report that boys of parents with cancer exhibited more externalizing problems, which further impair social functioning (9). Adolescents report a larger network of support including friends, counselors, teachers, and parents compared to elementary school children but also state they notice sacrificing doing something fun to stay at home due to increasing household responsibilities and caretaker roles (11, $14,15)$. Although the focus on social functioning typically revolves around negative aspects, there have been reports of positivity including children who exhibit posttraumatic growth and thrive despite the challenges and changes they endured (15).

\section{Interventions}

As cancer survivors live longer, an increasing number of patients and their families have begun to utilize everexpanding psycho-oncologic services (25). The burden of disease and often intense treatment regimens create barriers to open communication, which has been proven to be beneficial for all family members $(5,8,26)$. It is important to start with the parent's mental health, as children learn how to cope from them and a study of 194 adults with cancer reported a fall from $60 \%$ to $11 \%$ in adequately meeting their children's needs, leading to an increase in anxiety and depression $(11,27)$. Open communication, adaptability, expressiveness, cohesion, decreased conflict are all factors that have been found to be protective for children and adolescents $(8,28)$. The literature repeatedly shows that children and adolescents desire honest, accurate, and complete information, especially in regards to long term implications and the possibility of inheritance $(9,17,29,30)$. It is important to provide support to parents in how to explain their diagnosis in an age-appropriate manner and allowing children the opportunity to express their questions and concerns, as doing so results with better coping mechanisms and decreased distress (13). The introduction of coping strategies that include distraction, wishful thinking, spending time with parents, helping parents, and peer support also help decrease stress and distress $(13,27,31)$. For adolescents, providing avenues for them to connect to other peers in similar situations is important as adolescents report better support from friends whose parents also have cancer, as they find it difficult to relate or express ideas to their unaffected friends (15).

\section{Conclusion}

As more and more studies illuminate how cancer affects the family unit and its individual parts, it is apparent that more support is needed on multiple fronts. A multitude of studies have proven that interventions for parents, children, and the family unit as a whole have benefits. The topic of when to offer these interventions, however, is somewhat controversial. The specific interventions that are likely to have the largest benefits are still unclear (32). Nicholls et al. (17) identifies that the most unmet needs for these children are during the initial diagnostic stage and is complemented 
by another study (33) that shows parental stressors, and thereby stressors on these children, also decrease with time, suggesting that an early approach would be more beneficial. However, Romer et al. implemented an early curriculumbased intervention and concluded that these parents and their children are overwhelmed early and need time to adjust, cope, and establish a relationship with the medical staff for the intervention to be effective, suggesting a 3 month later approach as more beneficial (34).

The first step is providing the family with succinct, accurate and up-to-date information regarding their diagnosis. Parents and children can both be reluctant to talk about the diagnosis of cancer, trying to protect each other or just outright avoiding unpleasant discussions. It is crucial to offer opportunities of open communication for these families, including group counseling and family therapy, but should also be expanded to include peer support groups and group intervention for children involved $(9,13,31)$.

Children should receive age-appropriate help in identifying the impact of cancer diagnosis, formulating and articulating their thoughts, and finding situational positives to improve resilience (18). Child life advocates and child psychologists should be consulted if available, as they are specially trained to pick up on behaviors and distress that may be overlooked or underreported by parents, teachers, and physicians. Child-centered classes have shown benefit, as a short 6-week curriculum based study of 194 families focused on children found vast improvement in communication skills (87\%), school scores $(73 \%)$, and reduced anxiety (84\%) (29).

For families with adolescent-aged children, openly discussing roles in regards to household chores and family responsibilities instead of requiring adolescents to take on increased responsibilities may help reduce the burden felt by teens. It may be beneficial to encourage some home health care to provide relief for caregivers, allowing time for adolescent children to pursue their own interests and continue developing their social network.

The timing of these interventions is still being studied. One side of the discussion is to offer referrals and help right away, to lessen the burden on the family and encourage the production of positive coping methods. Early discussion can also direct patients and their families to accurate information, dispelling rumors or information that is not scientifically proven to be beneficial. The main argument against early intervention is that there has not been enough time to build a great physician-family rapport in the acute phase of a cancer diagnosis. Open communication relies on mutual trust and respect, which can take time to build with the entire affected family. The other argument is that there is simply too much going on at the time of diagnosis for other referrals to be effective. Often, cancer diagnoses involve referrals to medical and radiation oncologists, social workers, financial advisers, dieticians, dentists, psychiatrists, and primary care doctors. The overwhelming amount of information and upfront medical appointments, not to mention dealing with the recent diagnosis of cancer itself, often forces the patient to use the referrals directly involved in the definitive treatment of the cancer and not their families of their mental wellbeing.

As more and more families are affected by cancer, it is essential that we have a framework of healthcare professionals ready to step in to support the afflicted patient as well as their family. The emergence of new consortiums centered on patients involving panels of doctors, nurses, dieticians, counselors, financial advisors, social workers and spiritual advisors is an excellent step forward in providing comprehensive care to patient in a trying time of life.

\section{References}

1 Howlader N, Noone AM, Krapcho M, Miller D, Bishop K, Altekruse SF, Kosary CL, Yu M, Ruhl J, Tatalovich Z, Mariotto A, Lewis DR, Chen HS, Feuer EJ and Cronin KA (eds): SEER Cancer Statistics Review, 1975-2013, National Cancer Institute. Bethesda, MD, http://seer.cancer.gov/csr/1975_2013/, based on November 2015 SEER data submission, posted to the SEER web site, April 2016.

2 Weaver KE, Rowland JH, Alfano CM and Mcneel TS: Parental cancer and the family: a population-based estimate of the number of US cancer survivors residing with their minor children. Cancer 116(18): 4395-4401, 2010.

3 Siegel RL, Miller KD and Jemal A: Cancer statistics, 2016. CA Cancer J Clin 66(1): 7-30, 2016.

4 Compas BE, Worsham NL, Epping-Jordan JE, Grant KE, Mireault G, Howell DC and Malcarne VL: When mom or dad has cancer: markers of psychological distress in cancer patients, spouses, and children. Health Psychol 13(6): 507-515, 1994.

5 Huizinga GA, Visser A, Van der graaf WT, Hoekstra HJ, Stewart RE and Hoekstra-weebers JE: Family-oriented multilevel study on the psychological functioning of adolescent children having a mother with cancer. Psychooncology 20(7): 730-7, 2011.

6 Huizinga GA, Visser A, van der Graaf WT, Hoekstra HJ, Klip EC, Pras E and Hoekstra-Weebers JE: Stress response symptoms in adolescent and young adult children of parents diagnosed with cancer. Eur J Cancer 41(2): 288-295, 2005.

7 Osborn T: The psychosocial impact of parental cancer on children and adolescents: a systematic review. Psychooncology 16(2): 101-126, 2007.

8 Huizinga GA, Visser A, Van der graaf WT, Hoekstra HJ and Hoekstra-weebers JE: The quality of communication between parents and adolescent children in the case of parental cancer. Ann Oncol 16(12): 1956-1961, 2005.

9 Korneluk YG and Lee CM: Children's adjustment to parental physical illness. Clin Child Fam Psychol Rev 1(3): 179-193, 1998.

10 Johnson L: Developmental strategies for councelling the child whose parent or sibling has cancer. J Couns Dev 75: 417-427, 1997.

11 Visser A, Huizinga GA, Van der graaf WT, Hoekstra HJ and Hoekstra-weebers JE (2004): The impact of parental cancer on children and the family: a review of the literature. Cancer Treat Rev 30(8): 683-694, 2004. 
12 Armistead L, Klein K and Forehand R: Parental physical illness and child functioning. Clin Psychol Rev 15: 409-422, 1995.

13 Morris JN, Martini A and Preen D: The well-being of children impacted by a parent with cancer: an integrative review. Support Care Cancer 24(7): 3235-3251, 2016.

14 Kennedy VL and Lloyd-Williams M: How children cope when a parent has advanced cancer. Psychooncology 18(8): 886-892, 2009.

15 Phillips F: The experience of adolescents who have a parent with advanced cancer: A phenomenological inquiry. Palliat Support Care 13(4): 1057-1069, 2015.

16 Grabiak BR, Bender CM and Puskar KR: The impact of parental cancer on the adolescent: an analysis of the literature. Psychooncology 16(2): 127-137, 2007.

17 Nicholls W, Patterson P, Mcdonald FE and Hulbert-williams NJ: Unmet needs in young adults with a parent with a chronic condition: a mixed-method investigation and measure development study. Scand J Caring Sci 31(1): 191-200, 2017.

18 Visser A, Huizinga GA, Hoekstra HJ, Van der graaf WT and Hoekstra-weebers JE: Parental cancer: characteristics of parents as predictors for child functioning. Cancer 106(5): 1178-1187, 2006.

19 Phillips $\mathrm{F}$ and Lewis FM: The adolescent's experience when a parent has advanced cancer: a qualitative inquiry. Palliat Med 29(9): 851-858, 2015.

20 Ollonen P, Lehtonen J and Eskelinen M: Stressful and adverse life experiences in patients with breast symptoms; a prospective case-control study in Kuopio, Finland. Anticancer Res 25(1B): 531-536, 2005.

21 Ollonen P, Lehtonen J and Eskelinen M: Anxiety, depression and the history of psychiatric symptoms in patients with breast disease: a prospective case-control study in Kuopio, Finland. Anticancer Res 25(3c): 2527-2534, 2005.

22 Eskelinen M and Ollonen P: Life stress due to losses and deficit in childhood and adolescence as breast cancer risk factor: a prospective case-control study in Kuopio, Finland. Anticancer Res 30(10): 4303-4308, 2010

23 Hodges LJ, Humphris GM and Macfarlane G: A meta-analytic investigation of the relationship between the psychological distress of cancer patients and their carers. Soc Sci Med 60(1): 1-12, 2005.

24 Vachon M: Psychosocial distress and coping after cancer treatment. Cancer Nurs 29(2 Suppl): 26-31, 2006.
25 Kash KM, Mago R and Kunkel EJ: Psychosocial oncology: supportive care for the cancer patient. Semin Oncol 32(2): 211218, 2005.

26 Kennedy VL and Lloyd-williams M: Information and communication when a parent has advanced cancer. J Affect Disord 114(1-3): 149-155, 2009.

27 Moore CW, Rauch PK, Baer L, Pirl WF and Muriel AC: Parenting changes in adults with cancer. Cancer 121(19): 35513557, 2015.

28 Thastum M, Johansen MB, Gubba, L, Olesen, LB and Romer G: Coping, social relations, and communication: A qualitative exploratory study of children of parents with cancer. Clin Child Psych Psychiatry 13(1): 123-138, 2008.

29 Phillips F and Prezio EA: Wonders \& Worries: evaluation of a child centered psychosocial intervention for families who have a parent/primary caregiver with cancer. Psychooncology, 2016. doi: 10.1002/pon.4120. [Epub ahead of print]

30 Prchal A and Landolt MA: Psychological interventions with siblings of pediatric cancer patients: a systematic review. Psychooncology 18(12): 1241-1251, 2009.

31 Thastum M, Munch-hansen A, Wiell A and Romer G: Evaluation of a focused short-term preventive counselling project for families with a parent with cancer. Clin Child Psychol Psychiatry 11(4): 529-542, 2006.

32 Ellis SJ, Wakefield CE, Antill G, Burns M and Patterson P: Supporting children facing a parent's cancer diagnosis: a systematic review of children's psychosocial needs and existing interventions. Eur J Cancer Care 26: e12432, 2016.

33 Hagedoorn M, Kreicbergs U and Appel C: Coping with cancer: The perspective of patients' relatives. Acta Oncol 50(2): 205211, 2011.

34 Romer G, Saha R, Haagen M, Pott M, Baldus C and Bergelt C: Lessons learned in the implementation of an innovative consultation and liaison service for children of cancer patients in various hospital settings. Psychooncology 16(2): 138-148, 2007.

Received May 18, 2017

Revised June 24, 2017

Accepted June 26, 2017 